\title{
INFLUÊNCIA DO ACABAMENTO SUPERFICIAL NA DESINFECÇÃO DE SUPERFÍCIES EXTERNAS DE RESINA ACRÍLICA TERMOPOLIMERIZÁVEL
}

\author{
${ }^{1}$ Iara Augusta Orsi, ${ }^{2}$ Adalton García, ${ }^{3}$ Camilo Andrés Villabona López, ${ }^{4}$ Izabel Yoko Ito. \\ ${ }^{1}$ Professora Doutora F. Odontologia Ribeirão Preto U São Paulo. ${ }^{2}$ Mestre em Reabilitação Oral F. Odontologia Ribeirão Preto U. São Paulo. \\ ${ }^{3}$ Professor F. de Odontologia U. Santo Tomás, pós-graduando, nível mestrado em Reabilitação Oral U. São Paulo, Ribeirão Preto. \\ ${ }^{4}$ Professora Titular F. Ciências Farmacêuticas de Ribeirão Preto U. São Paulo.
}

\author{
Autor responsable de correspondencia: Iara Augusta Orsi \\ Correo electrónico: iaraorsi@forp.usp.br
}

\section{RESUMO}

Objetivo: Avaliar a influência do acabamento superficial na desinfecção de superfícies externas de resina acrílica termopolimerizável e determinar o período necessário para desinfecção.

Materiais e métodos: Foram confeccionados 250 corpos-de-prova retangulares $(65 \times 10 \times 3 \mathrm{~mm})$, uma das faces do corpo-de-prova recebeu acabamento com lixas de carborundum e polimento com pastas de pedra-pomes/água e óxido de zinco/água, a outra face não recebeu tratamento, simulando as faces de uma prótese total. Após esterilização com óxido de etileno, os corpos-de-prova foram imersos por 24 horas em meios de cultura contendo cepas de Staphylococcus aureus, Pseudomonas aeruginosa, Candida albicans, Streptococcus mutans e Enterococcus faecalis. Decorrido esse período, os corpos-de-prova eram lavados com água esterilizada e desinfetados por períodos de 5, 10 e 15 minutos com hipoclorito de sódio $1 \%$ e $2 \%$ e glutaraldeído a $2 \%$. A seguir eram realizadas culturas de contato das superfícies externas, lisa e rugosa, e incubação por 20 dias; o crescimento microbiano era avaliado pela método visual. Para análise estatística foi utilizado o Teste Exato de Fisher comparando as amostras duas a duas.

Resultados: Não houve diferença estatística entre as soluções desinfetantes, períodos de desinfecção e microrganismos analisados. Conclusões: O período de 10 minutos foi adequado para desinfecção das superfícies externas de resina acrílica com todas as soluções desinfetantes avaliadas e a eficácia da desinfecção não foi influenciada pelo acabamento e polimento das superfícies. [Orsi IA, García $\mathrm{AD}$, Villabona CA, Ito IY. Influência do acabamento superficial na desinfecção de superfícies externas de resina acrílica termopolimerizável. Ustasalud 2010; 9: 18 - 25]

Palavras-chave: Desinfecção química, Resina acrílica, Prótese total, Glutaraldeído, Hipoclorito de sódio.

\section{INFLUENCE OF SURFACE TREATMENTS IN THE DISINFECTION OF THE EXTERNAL SURFACES OF THERMOPOLYMERIZED ACRYLIC RESINS}

\section{ABSTRACT}

Objective: To evaluate the influence of surface treatments in the disinfection of the external surfaces of thermopolymerized acrylic resin and determine the time required for disinfection.

Methods: Two hundred and fifty rectangular specimens were fabricated $(65 \times 10 \times 3 \mathrm{~mm})$, one side of the specimen was polished with silicon carbide paper and rag wheel and polishing pastes (pumice and water, followed by zinc oxide and water), the other side received no treatment, thus simulating both sides of a complete denture.After sterilization with ethylene oxide, the specimens were immersed for 24 hours in culture media containing strains of Staphylococcus aureus, Pseudomonas aeruginosa, Candida albicans, Streptococcus mutans and Enterococcus faecalis. After this period, the specimens were rinsed with sterile water and disinfected for 5, 10 and 15 minutes with $1 \%$ and $2 \%$ sodium hypochlorite and $2 \%$ glutaraldehyde. Then they were cultured in contact of the external surfaces, smooth and rough, and incubated for 20 days, microbial growth was evaluated by visual method.Statistical analysis was performed using the Fisher exact test comparing the two samples to two.

Results: There was no statistical difference between the disinfectant solutions, the disinfection times and microorganisms analyzed. Conclusion: It is concluded that the period of 10 minutes was adequate for disinfection of the external surfaces of acrylic resin with all disinfectant solutions evaluated and finishing and polishing surfaces did not influence the effectiveness of disinfection.

Key words: Chemical disinfection, Acrylic resin, Complete denture, Glutaraldheyde, Sodium hypochlorite. 


\section{INTRODUÇÃO}

Uma das áreas da odontologia que oferece os maiores riscos de infecção cruzada é a prótese dentária. Na confecção de peças protéticas, diversos materiais, instrumentos e equipamentos são usados e não podem ser esterilizados ${ }^{1}$ expondo os profissionais e pacientes ao risco de infecção cruzada. ${ }^{2-3}$

Na etapa final da confecção de próteses totais e parciais removíveis, o técnico de laboratório odontológico realiza o acabamento e polimento somente da superfície externa da prótese. A superfície interna não recebe acabamento, as porosidades e/ou irregularidades desta superfície são deixadas para permitir seu íntimo contato com a mucosa favorecendo a retenção do aparelho na cavidade bucal, contudo facilita a adesão e retenção de microrganismos nessa superfície.

Pesquisas têm demonstrado que diferentes graus de polimento de resinas acrílicas podem influenciar na aderência de microrganismos. Os estudos de Radford et $\mathrm{al}^{4}{ }^{4}$ e Taylor et $\mathrm{al},{ }^{5}$ relataram maior adesão de Candida albicans em superficies rugosas de resina acrílica e que as irregularidades da superfície rugosa aumentam a área de superfície e facilitam a retenção de microrganismos. Kagermeier-Callaway et al. evidenciaram maior quantidade de Actinomyces viscosus e de Streptococcus oralis aderidos respectivamente nas superficies não-polidas e polidas da resina acrílica ${ }^{6}$. Essas observações foram relacionadas às variações da energia livre da superfície e à hidrofobicidade dos microrganismos e do material.

Diversos estudos têm sido realizados para avaliar a eficácia da desinfecção de resina acrílica termopolimerizável. Em 1984, Rudd et al. determinaram que 5 minutos de imersão em hipoclorito de sódio a 5,25\% é capaz de desinfetar uma prótese total ${ }^{7}$. Henderson et al. relataram que a imersão por 10 minutos em glutaraldeído a $2 \%$ (Sporicidin) ou hipoclorito de sódio a 5,25\% (Clorox) foi eficaz para desinfecção de próteses parciais removíveis ${ }^{8}$. Esse mesmo período foi relatado por Chau et al. como suficiente para desinfecção das superfícies externas de resina acrílica em hipoclorito de sódio a $0,525 \%{ }^{9}$. Os resultados do estudo de Bell et al. mostraram desinfecção de resina com dióxido de cloro e hipoclorito de sódio a $5,25 \%$ em 2 e 4 minutos, respectivamente. ${ }^{10}$

Devido às controvérsias sobre o período necessário para desinfecção e falta de informação quanto à eficácia das soluções químicas na desinfecção das superfícies lisas e rugosas de resinas acrílicas, este estudo teve como objetivo avaliar a influência do acabamento superficial na desinfecção de superficies externas de resina acrílica termopolimerizável e determinar o período necessário para desinfecção.

\section{MATERIAL E MÉTODO}

Duzentos e cinqüenta corpos-de-prova retangulares $(65 \times 10 \times 3 \mathrm{~mm})$ foram confeccionados em resina acrílica termopolimerizável Lucitone 550 (Dentsply Ind. e Com. Ltda, Petrópolis, Brasil), correspondentes a 225 corpos-de-prova experimentais e 25 controles. Uma face do corpo-de-prova recebeu acabamento com lixas de carborundum ( $\mathrm{n}^{\text {os }} 120,400,600$ e 1200) e polimento com rodas, feltros e pastas de pedrapomes/água e óxido de zinco/água; a outra face não recebeu acabamento, simulando assim as superficies de uma prótese total. Os corpos-de-prova foram submetidos à esterilização com óxido de etileno (Figura 1) e divididos em cinco grupos de 50 corpos-de-prova (45 do grupo experimental e 5 do grupo controle), correspondentes às cinco cepas microbianas: Staphylococcus aureus (ATCC 6538), Pseudomonas aeruginosa (ATCC 2327), Candida albicans (ATCC 1023), Streptococcus mutans (ATCC 25175) e Enterococcus faecalis (ATCC 10541).

Após a esterilização, cada corpo-de-prova foi colocado assepticamente em um tubo de ensaio $(18 \times 180 \mathrm{~mm})$ esterilizado (Figura 2$)$ e contaminado em $15 \mathrm{~mL}$ de meio de cultura contendo uma das cepas (Figura 3), em seguida, os tubos foram colocados em uma mesa com agitação orbital (Marconi, Piracicaba, São Paulo, Brasil) por um período de 24 horas (Figura 4). Decorrido esse período, os tubos foram removidos e a turvação do meio era avaliada para verificar o crescimento microbiano.

\section{Grupo Experimental}

Assepticamente, o meio de cultura era removido do tubo de ensaio (Figura 5), o corpo-de-prova era lavado com água esterilizada e colocado em placa de Petri com compressas de gaze esterilizadas (Figura $6,7)$. A seguir, era transferido para um tubo Falcon $(50 \mathrm{~mL})$ esterilizado (Corning, Nova York, EUA) (Figura 8), onde a solução desinfetante $(40 \mathrm{~mL})$ era adicionada (Figura 9). Cada corpo-de-prova ficava imerso na solução desinfetante por períodos de 5,10 e 15 minutos. Foram utilizadas soluções de hipoclorito de sódio a 1\% (Biodinâmica Química e Farmacêutica Ltda., Ibiporã, Paraná, Brasil) e 2\% (Biopharma, Uberlândia, Minas Gerais, Brasil) e glutaraldeído a 2\% (Cidex, Johnson \& Johnson Produtos Profissionais Ltda., São José dos Campos, São Paulo, Brasil) (Figura 1).

Após a desinfecção (Figura 10), cada corpo-de-prova era colocado em placa de Petri com compressas de gaze esterilizadas para remover o excesso de solução química (Figura 11). Eram realizadas culturas de contato das superfícies lisa e rugosa dos corposde-prova em placas de Petri com meio de cultura (Figura 12). Para os microrganismos Staphylococcus 
aureus, Pseudomonas aeruginosa e Candida albicans foi utilizado o meio de cultura Mueller Hinton Ágar (Difco Laboratories, Detroit, EUA); para Streptococcus mutans e Enterococcus faecalis, Brain Heart Infusion adicionado de ágar (Difco Laboratories, Detroit, EUA).

As placas de Petri foram incubadas a $35^{\circ} \mathrm{C}$, sendo que as placas utilizadas para os microrganismos Streptococcus mutans e Enterococcus faecalis foram colocadas em microaerofilia $\left(5 \% \mathrm{CO}_{2}\right)$. A primeira avaliação foi realizada após 48 horas, e as seguintes em intervalos de 72 horas, até que se completassem vinte dias (Figura 13). O crescimento era registrado como positivo, e as colônias representativas eram semeadas em placas de Petri com meios de cultura seletivos.

\section{Grupo Controle}

Assepticamente, o meio de cultura era removido do tubo de ensaio, o corpo-de-prova era lavado com água esterilizada e colocado em uma placa de Petri com compressas de gaze esterilizadas. Em seguida, eram realizadas culturas de contato das faces lisa e rugosa do corpo-de-prova em placa de Petri com os meios de cultura utilizados no grupo experimental e incubação a $35^{\circ} \mathrm{C}$. Era verificado o crescimento microbiano pelo exame visual e a recuperação dos microrganismos em meios de cultura seletivos.

\section{Análise estatística}

A análise estatística dos resultados empregou o Teste Exato de Fisher realizando comparações entre as superfícies lisas e rugosas, cepas microbianas, soluções desinfetantes e períodos de desinfecção.

\section{RESULTADOS}

As Tabelas 1, 2 e 3 apresentam os resultados da desinfecção das superfícies externas lisas e rugosas da resina acrílica nos períodos de 5,10 e 15 minutos, respectivamente.

Não houve diferença estatisticamente significante entre as comparações realizadas.

Tabela 1. Resultados da análise do crescimento microbiano das superfícies externas após 5 minutos de desinfecção química.

\begin{tabular}{|c|c|c|c|c|c|c|c|}
\hline \multirow{3}{*}{ Microrganismo } & \multicolumn{6}{|c|}{ Soluções Desinfetantes } & \multirow{3}{*}{$\begin{array}{c}\text { Grupo } \\
\text { controle }\end{array}$} \\
\hline & \multicolumn{2}{|c|}{ Hipoclorito de sódio a $1 \%$} & \multicolumn{2}{|c|}{ Hipoclorito de sódio a 2\% } & \multicolumn{2}{|c|}{ Glutaraldeído a 2\% } & \\
\hline & superf. lisa & superf. rugosa & superf. lisa & superf. rugosa & superf. lisa & superf. rugosa & \\
\hline \multirow{5}{*}{ S. aureus } & - & - & - & - & - & - & + \\
\hline & - & - & - & - & - & - & + \\
\hline & - & - & - & - & - & - & + \\
\hline & - & - & - & - & - & - & + \\
\hline & - & - & - & - & - & - & + \\
\hline \multirow{5}{*}{ P. aeruginosa } & - & - & - & - & - & - & + \\
\hline & - & - & + & + & - & - & + \\
\hline & - & - & - & - & - & - & + \\
\hline & - & - & - & - & - & - & + \\
\hline & - & - & - & - & - & - & + \\
\hline \multirow{5}{*}{ S. mutans } & - & - & - & - & - & - & + \\
\hline & - & - & - & - & - & - & + \\
\hline & - & - & - & - & - & - & + \\
\hline & - & - & - & - & - & - & + \\
\hline & - & - & - & - & - & - & + \\
\hline \multirow{5}{*}{ E. faecalis } & - & - & - & - & - & - & + \\
\hline & - & - & - & - & - & - & + \\
\hline & - & - & - & - & - & - & + \\
\hline & - & - & - & - & - & - & + \\
\hline & - & - & - & - & - & - & + \\
\hline \multirow{5}{*}{ C. albicans } & - & - & - & - & - & - & + \\
\hline & - & - & - & - & - & - & + \\
\hline & - & - & - & - & - & - & + \\
\hline & - & - & - & - & - & - & + \\
\hline & - & - & - & - & - & - & + \\
\hline
\end{tabular}

- = negativo; + = positivo 


\section{ARTÍCULO ORIGINAL}

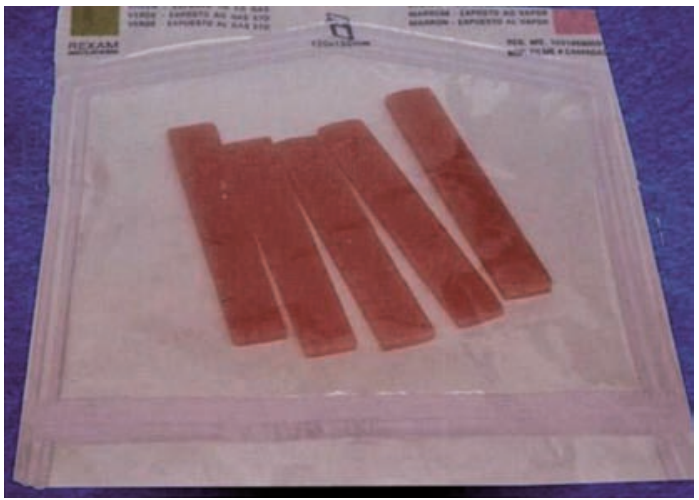

Figura 1. Esterilização dos corpos -de- prova com óxido de etileno.

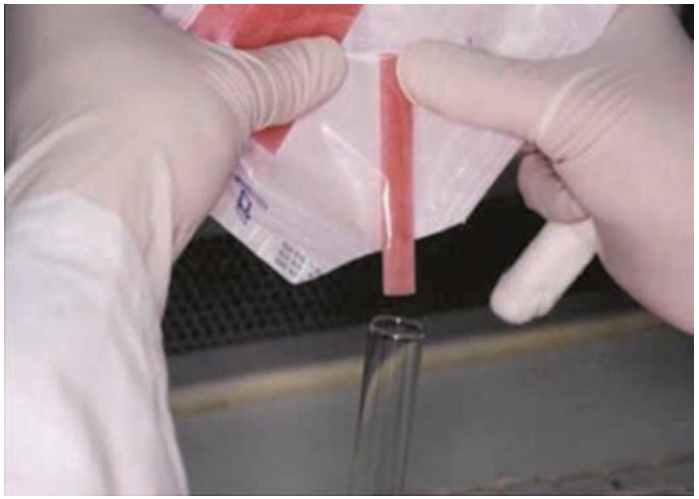

Figura 2. Corpos -de- prova colocados assepticamente em tubos de ensaio.

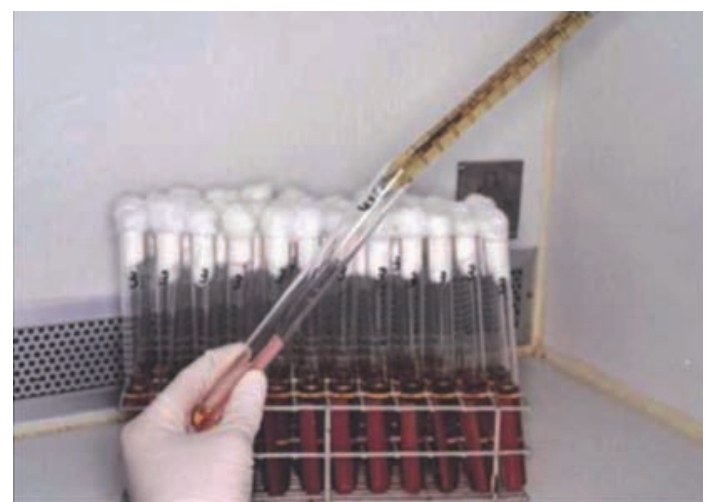

Figura 3. Meios de cultura com as cepas microbianas colocados nos tubos de ensaio.

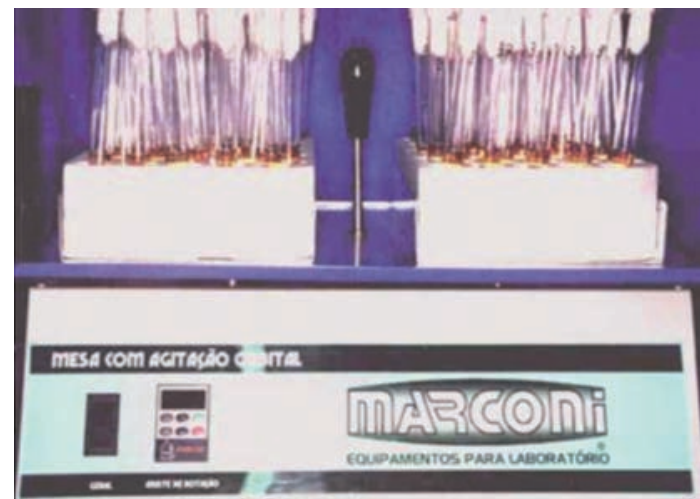

Figura 4. Tubos de ensaio posicionados em mesa com agitação orbital.

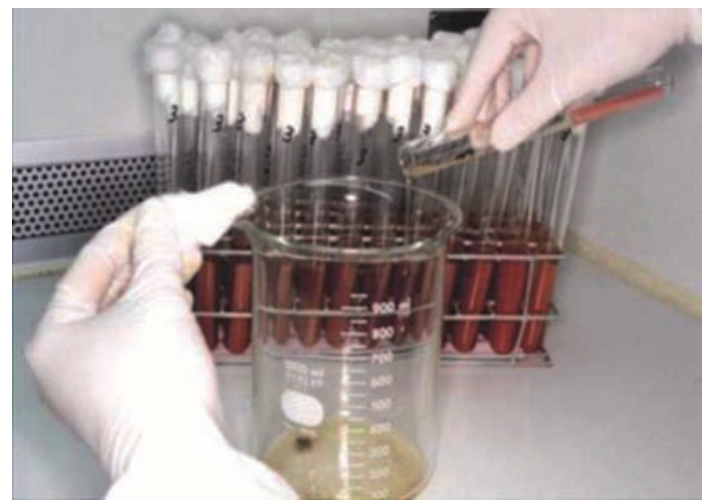

Figura 5. Remoção do meio de cultura de maneira asséptica.

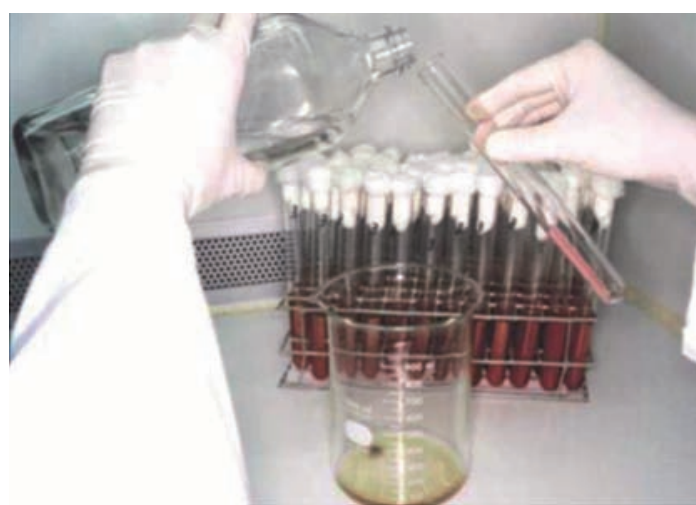

Figura 6. Corpo-de- prova sendo lavados com agua destilada. 


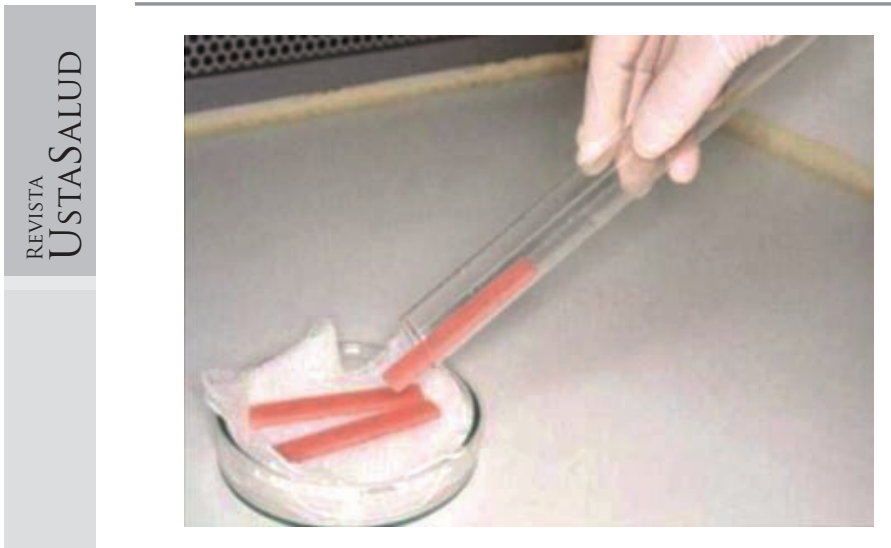

Figura 7. Corpos-de-prova colocados em placa de Petri com gaze esterilizada.

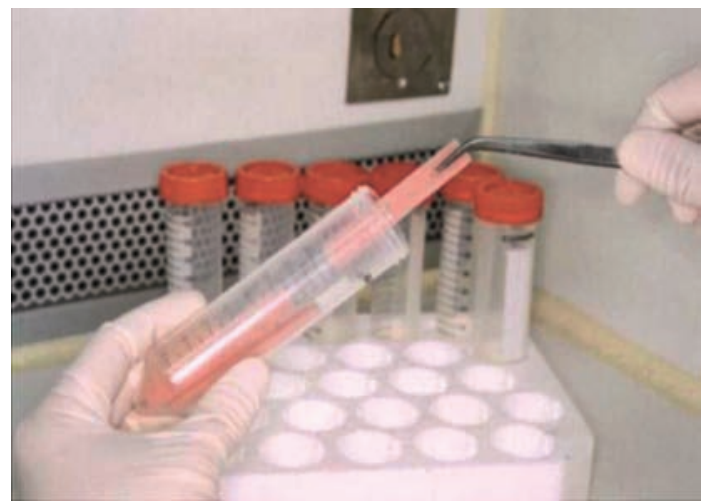

Figura 8. Corpo -de- prova colocado em tubo tipo Falcon.

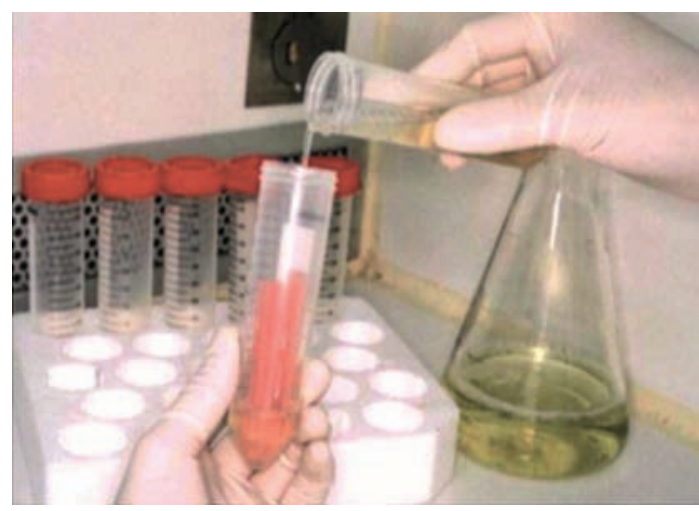

Figura 9. Adição da solução desinfetante.

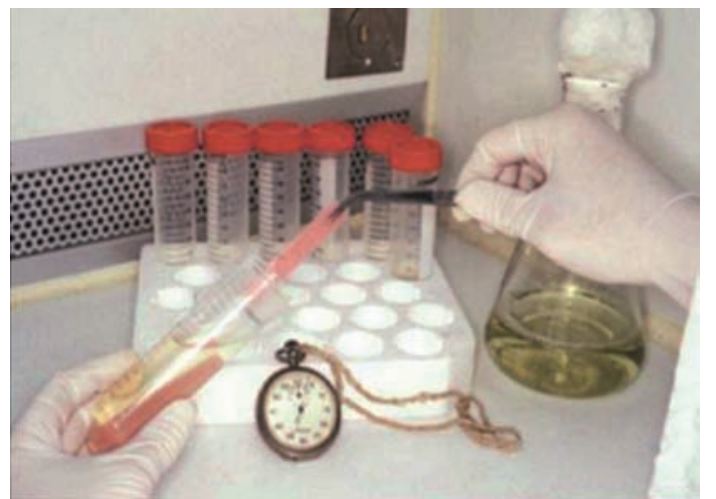

Figura 10. Remoção dos corpos -de- prova do tubo com solução desinfetante.

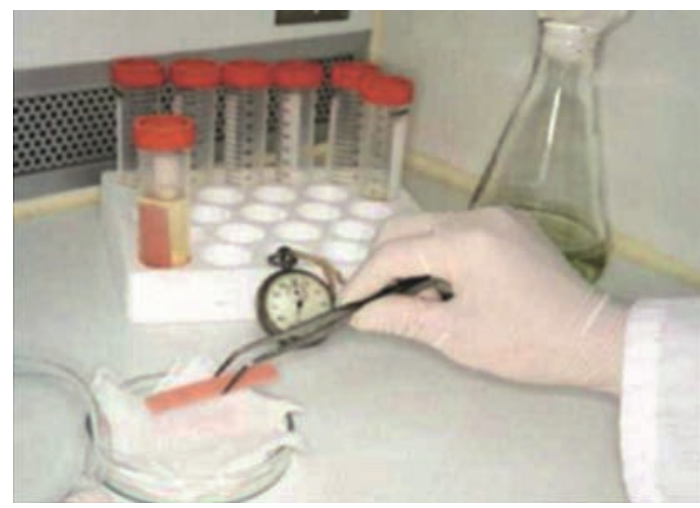

Figura 11. Remoção do excesso das soluções desinfetantes.

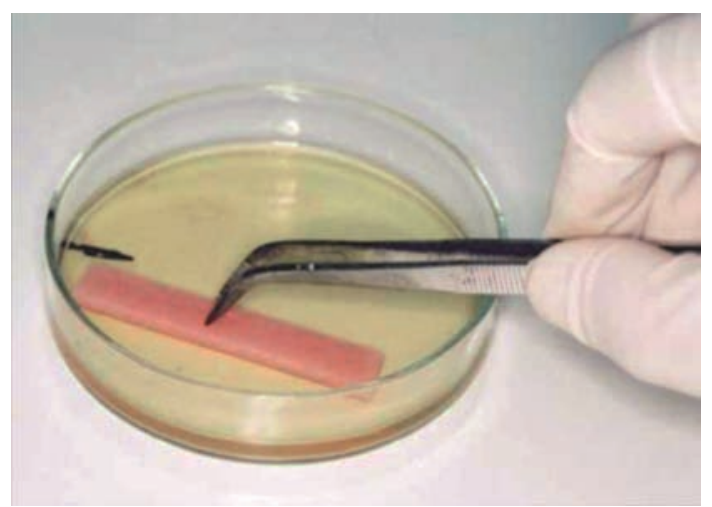

Figura 12. Cultura de contato das superficies lisa e rugosa.

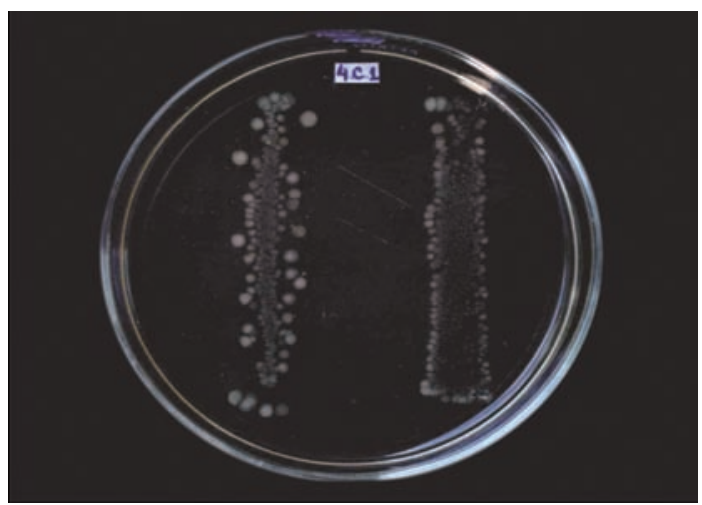

Figura 13. Exame visual da cultura de contato. 


\section{ARTÍCULO ORIGINAL}

Tabela 2. Resultados da análise do crescimento microbiano das superfícies externas após 10 minutos de desinfeç̧ão química.

\begin{tabular}{|c|c|c|c|c|c|c|c|}
\hline \multirow{3}{*}{ Microrganismo } & \multicolumn{6}{|c|}{ Soluções Desinfetantes } & \multirow{3}{*}{$\begin{array}{c}\text { Grupo } \\
\text { controle }\end{array}$} \\
\hline & \multicolumn{2}{|c|}{ Hipoclorito de sódio a $1 \%$} & \multicolumn{2}{|c|}{ Hipoclorito de sódio a $2 \%$} & \multicolumn{2}{|c|}{ Glutaraldeído a 2\% } & \\
\hline & superf. lisa & superf. rugosa & superf. lisa & superf. rugosa & superf. lisa & superf. rugosa & \\
\hline \multirow{5}{*}{ S. aureus } & - & - & - & - & - & - & + \\
\hline & - & - & - & - & - & - & + \\
\hline & - & - & - & - & - & - & + \\
\hline & - & - & - & - & - & - & + \\
\hline & - & - & - & - & - & - & + \\
\hline \multirow{5}{*}{ P. aeruginosa } & - & - & - & - & - & - & + \\
\hline & - & - & - & - & - & - & + \\
\hline & - & - & - & - & - & - & + \\
\hline & - & - & - & - & - & - & + \\
\hline & - & - & - & - & - & - & + \\
\hline \multirow{5}{*}{ S. mutans } & - & - & - & - & - & - & + \\
\hline & - & - & - & - & - & - & + \\
\hline & - & - & - & - & - & - & + \\
\hline & - & - & - & - & - & - & + \\
\hline & - & - & - & - & - & - & + \\
\hline \multirow{5}{*}{ E. faecalis } & - & - & - & - & - & - & + \\
\hline & - & - & - & - & - & - & + \\
\hline & - & - & - & - & - & - & + \\
\hline & - & - & - & - & - & - & + \\
\hline & - & - & - & - & - & - & + \\
\hline \multirow{5}{*}{ C. albicans } & - & - & - & - & - & - & + \\
\hline & - & - & - & - & - & - & + \\
\hline & - & - & - & - & - & - & + \\
\hline & - & - & - & - & - & - & + \\
\hline & - & - & - & - & - & - & + \\
\hline
\end{tabular}

- = negativo; + = positivo

Tabela 3. Resultados da análise do crescimento microbiano das superfícies externas após 15 minutos de desinfecção química.

\begin{tabular}{|c|c|c|c|c|}
\hline \multirow{3}{*}{ Microrganismo } & \multicolumn{3}{|c|}{ Soluções Desinfetantes } & \multirow{3}{*}{$\begin{array}{c}\text { Grupo } \\
\text { controle }\end{array}$} \\
\hline & Hipoclorito de sódio a $1 \%$ & Hipoclorito de sódio a $2 \%$ & Glutaraldeído a 2\% & \\
\hline & superf. lisa superf. rugosa & superf. lisa superf. rugosa & superf. lisa superf. rugosa & \\
\hline
\end{tabular}

\begin{tabular}{|c|c|c|c|c|c|c|c|}
\hline \multirow{5}{*}{ S. aureus } & - & - & - & - & - & - & + \\
\hline & - & - & - & - & - & - & + \\
\hline & - & - & - & - & - & - & + \\
\hline & - & - & - & - & - & - & + \\
\hline & - & - & - & - & - & - & + \\
\hline \multirow{5}{*}{ P. aeruginosa } & - & - & - & - & - & - & + \\
\hline & - & - & - & - & - & - & + \\
\hline & - & - & - & - & - & - & + \\
\hline & - & - & - & - & - & - & + \\
\hline & - & - & - & - & - & - & + \\
\hline \multirow{5}{*}{ S. mutans } & - & - & - & - & - & - & + \\
\hline & - & - & - & - & - & - & + \\
\hline & - & - & - & - & - & - & + \\
\hline & - & - & - & - & - & - & + \\
\hline & - & - & - & - & - & - & + \\
\hline \multirow{5}{*}{ E. faecalis } & - & - & - & - & - & - & + \\
\hline & - & - & - & - & - & - & + \\
\hline & - & - & - & - & - & - & + \\
\hline & - & - & - & - & - & - & + \\
\hline & - & - & - & - & - & - & + \\
\hline \multirow{5}{*}{ C. albicans } & - & - & - & - & - & - & + \\
\hline & - & - & - & - & - & - & + \\
\hline & - & - & - & - & - & - & + \\
\hline & - & - & - & - & - & - & + \\
\hline & - & - & - & - & - & - & + \\
\hline
\end{tabular}

- = negativo; $+=$ positivo 
Tabela 4 - Resultados do Teste Exato de Fisher na desinfecção das superfícies externas lisas e rugosas após imersão nas soluções químicas em diferentes períodos de imersão.

\begin{tabular}{|c|c|c|c|c|c|c|c|c|c|}
\hline \multirow{4}{*}{ Superfícies Externas } & \multicolumn{9}{|c|}{ Soluções Desinfetantes } \\
\hline & \multicolumn{3}{|c|}{ Hipoclorito $1 \%$} & \multicolumn{3}{|c|}{ Hipoclorito $2 \%$} & \multicolumn{3}{|c|}{ Glutaraldeído $2 \%$} \\
\hline & \multicolumn{9}{|c|}{ Tempo (min) } \\
\hline & 5 & 10 & 15 & 5 & 10 & 15 & 5 & 10 & 15 \\
\hline Lisa $\mathrm{x}$ Rugosa & ns & ns & ns & ns & ns & ns & ns & ns & ns \\
\hline
\end{tabular}

ns = não significante $(\alpha>0,05 \%)$

\section{DISCUSSÃo}

Para avaliar a eficácia das soluções químicas foram utilizadas cinco cepas de microrganismos, comumente empregadas na avaliação da eficácia de biocidas. A utilização desses microrganismos está de acordo com Ascenji apud Furukawa et al. que recomenda como microrganismos indicadores Staphylococcus aureus, Pseudomonas aeruginosa e Candida albicans $^{11}$. Para que o microrganismo seja destruído, é necessário que quatro etapas de interação do germicida com a célula ocorram; inicialmente, deve ocorrer a adsorção da solução química pela célula, penetração e acúmulo do agente químico e em seguida a interação da substância química com as "estruturas-alvo". ${ }^{12}$ As soluções de hipoclorito de sódio agem primariamente nos microrganismos pela alteração química de suas proteínas e inativação dos ácidos nucléicos ${ }^{13}$ enquanto o glutaraldeído promove a alteração dos ácidos nucléicos e evita a passagem de nutrientes para o interior das células. ${ }^{13-14}$

Neste estudo, a imersão por 5 minutos em glutaraldeído a $2 \%$ desinfetou as superfícies externas lisas e rugosas dos corpos-de-prova, resultados diferentes foram descritos no estudo de Henderson et al. ${ }^{8}$ que relataram a desinfecção de próteses totais e parciais removíveis com glutaraldeído a $2 \%$ em 10 minutos de imersão. Tal diferença pode estar relacionada à maior área de superfície das próteses em relação aos corpos-de-prova utilizados no estudo atual.

A desinfecção das superfícies externas lisa e rugosa da resina acrílica com o hipoclorito de sódio a $1 \%$ ocorreu em 5 minutos de imersão, esse mesmo período foi citado por Rudd et al. ${ }^{7}$ como eficaz para desinfecção de próteses totais com hipoclorito de sódio a $5,25 \%$. Resultados diferentes foram descritos no estudo de Bell et al. ${ }^{10}$ que mostrou a desinfecção de superfícies externas de resina acrílica, na presença de material orgânico, com hipoclorito de sódio a 5,25\% em 4 minutos. Esse menor tempo de desinfecção pode ser devido à maior concentração da solução utilizada e à análise do crescimento microbiano após pequeno período de incubação (3 dias).

Embora não exista diferença estatística entre as comparações, a desinfecção das superficies externas lisa e rugosa da resina acrílica com o hipoclorito de sódio a 1 e $2 \%$ ocorreu em 5 e 10 minutos, respectivamente; tais resultados podem estar relacionados com o pH das soluções.

Diversos fatores como concentração e tipo de microrganismos $^{15-16}$, presença de material orgânico, natureza do objeto (se possui poros), temperatura e $\mathrm{pH}$ da solução desinfetante ${ }^{17}$ devem ser considerados na desinfecção das próteses totais, pois podem influenciar na eficácia do procedimento.

Os estudos de Radford et al. ${ }^{4}$ Taylor et al. ${ }^{5}$ e Kagermeier-Callaway et. al. ${ }^{6}$ demonstraram que a rugosidade da resina acrílica pode influenciar a adesão de microrganismos nas superficies. Entretanto, verificou-se nesse estudo que as irregularidades não tiveram nenhum efeito na eficácia dos desinfetantes, pois as superficies externas lisas e rugosas foram desinfetadas com igual freqüência, evidenciando que as soluções foram capazes de destruir os microrganismos alojados em irregularidades e concavidades da superfície externa da resina acrílica nãopolida. Essas observações foram confirmadas por Chau et al. ${ }^{9}$ que relataram resultados semelhantes nas amostras de resina desinfetadas com Alcide LD e Biocide.

A Associação Dentária Americana (ADA) e o Centro de Controle de Doenças e Prevenção dos Estados Unidos (CDC) recomendam a desinfecção das próteses antes da entrega ao paciente e antes do retorno ao laboratório. ${ }^{18}$ De acordo com os resultados desse estudo, a desinfecção das superfícies externas das próteses totais recém-confeccionadas pode ser rea- 
lizada pela imersão por 10 minutos em uma das soluções químicas avaliadas.

\section{Conclusões}

A partir da análise dos resultados desse estudo, conclui-se que:

1. As soluções de hipoclorito de sódio a $1 \%$ e glutaraldeído a $2 \%$ foram eficazes com 5 minutos de imersão.

2. O período de 10 minutos foi adequado para desinfecção das superfícies externas de resina acrílica com todas as soluções desinfetantes avaliadas.

3. A eficácia da desinfecção não foi influenciada pela rugosidade das superfícies externas.

\section{REFERÊNCIAS BIBLIOGRÁFICAS}

1. Wakefield CW. Laboratory contamination of dental prostheses. J Prosthet Dent 1980; 44: 143 -146.

2. Kahn RC, Lancaster MV, Kate JR. The microbiologic cross contamination of dental prostheses. J Prosthet Dent 1982; 47: 556 - 559.

3. Connor C. Cross-contamination control in prosthodontic practice. Int J Prosthodont 1991; 4: 337 -344.

4. Radford DR, Sweet SP, Challacombe SJ, Walter JD. Adherence of Candida albicans to denture-base materials with different surface finishes. J Dent 1998; 26: 577 - 583.

5. Taylor R, Maryan C, Verran J. Retention of oral microorganisms on cobalt-chromium alloy and dental acrylic resin with different surface finishes. J Prosthet Dent 1998; 80: 592 - 597.

6. Kagermeier-Callaway AS, Willershausen B, Frank T, Stender $\mathrm{E}$. In vitro colonisation of acrylic resin denture base materials by Streptococcus oralis and Actinomyces viscosus. Int Dent J 2000; 50: 79 - 85.

7. Rudd RW, Senia ES, Mccleskey FK, Adams ED. Sterilization of complete dentures with sodium hypoclorite. J Prosthet. Dent 1984; 51: 318 - 321.

8. Henderson CW, Schwartz RS, Herbold ET, Mayhew RB. Evaluation of the barrier system, and infection control system for the dental laboratory. J Prosthet Dent 1987; 58: 517 - 521

9. Chau VB, Saunders TR, Pimsler M, Elfring DR. In-depth disinfection of acrylic resins. J Prosthet Dent 1995; 74: $309-313$.

10. Bell JA, Brockmann SL, Feil P, Sackuvich DA. The effectiveness of two disinfectants on denture base acrylic resin with an organic load. J Prosthet Dent 1989; 61: 580 - 589.

11. Furukawa KK, Niagro FD, Runyan DA, Cameron SM. Effectiveness of chlorine dioxide in disinfection on two soft denture liners. J Prosthet Dent 1998; 80: 723 - 729.

12. Denyer SP, Maillard JY. Cellular impermeability and uptake of biocides and antibiotics in gram-negative bacteria. J Appl Microbiol 2002; 92 supl: 35S - 45S.

13. Rutala WA. APIC guideline for selection and use of disinfectants. Am J Infect Control 1996; 24: 313 - 342.

14. Ciancio SG. Drugs in dentistry. Chemical sterilizing agents: glutaraldehydes. Dent Manage 1986; 26: 76 - 77.
15. Molinari JA, Runnells RR. Role of disinfectants in infection control. Dent Clin North Am 1991; 35: 323 - 337.

16. Molinari JA, Schaefer ME, Runnells RR. Chemical sterilization, disinfection, and antisepsis. In: Cottone, JA, Terezhalmy GT, Molinari JA. Practical Infection Control in Dentistry, Baltimore: Williams \& Wilkins; 1996. p. 161175.

17. Rutala WA, Weber DJ. Uses of inorganic hypochlorite (bleach) in health-care facilities. Clin Microbiol Rer 1997; 10: 597 - 610

18. Molinari JA, Merchant VA, Gleason M.J. Controversies in infection control. Dent Clin North Am 1990; 34: 55 - 69.

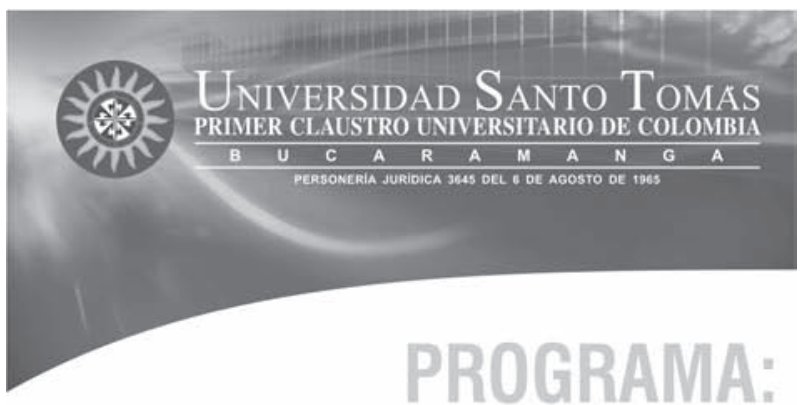

\section{ODONTOLOGÍA}

SNIES 1097

Acreditación de Alta Calidad 517 del 6 de febrero de 2008
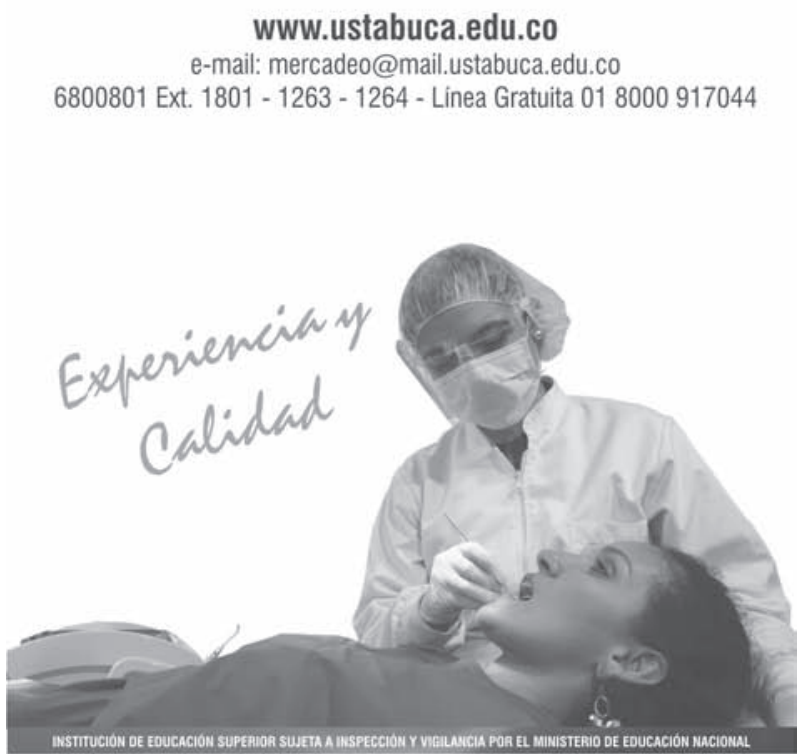